\title{
Decision Making When Cancer Becomes Chronic: Needs Assessment for a Web-Based Medullary Thyroid Carcinoma Patient Decision Aid
}

Danielle Shojaie ${ }^{1 *}$, MPH; Aubri S Hoffman ${ }^{2 *}$, MS, PhD; Ruth Amaku ${ }^{1}$, MPH; Maria E Cabanillas ${ }^{3}$, MD; Julie Ann $\mathrm{Sosa}^{4}$, MA, MD; Steven G Waguespack ${ }^{3}$, MD; Mark E Zafereo ${ }^{5}$, MD; Mimi I Hu${ }^{3}$, MD; Elizabeth E Grubbs ${ }^{1}$, MD, FACS

\footnotetext{
${ }^{1}$ Department of Surgical Oncology, The University of Texas MD Anderson Cancer Center, Houston, TX, United States

${ }^{2}$ Department of Gynecological Oncology and Reproductive Medicine, The University of Texas MD Anderson Cancer Center, Houston, TX, United States

${ }^{3}$ Department of Endocrine Neoplasia and Hormonal Disorders, The University of Texas MD Anderson Cancer Center, Houston, TX, United States

${ }^{4}$ Department of Surgery, University of California San Francisco, San Francisco, CA, United States

${ }^{5}$ Department of Head and Neck Surgery, The University of Texas MD Anderson Cancer Center, Houston, TX, United States

*these authors contributed equally
}

\section{Corresponding Author:}

Elizabeth E Grubbs, MD, FACS

Department of Surgical Oncology

The University of Texas MD Anderson Cancer Center

1400 Pressler Street, Unit 1484

Houston, TX, 77030

United States

Phone: 17137453715

Fax: 17137924689

Email: eggrubbs@mdanderson.org

\begin{abstract}
Background: In cancers with a chronic phase, patients and family caregivers face difficult decisions such as whether to start a novel therapy, whether to enroll in a clinical trial, and when to stop treatment. These decisions are complex, require an understanding of uncertainty, and necessitate the consideration of patients' informed preferences. For some cancers, such as medullary thyroid carcinoma, these decisions may also involve significant out-of-pocket costs and effects on family members. Providers have expressed a need for web-based interventions that can be delivered between consultations to provide education and prepare patients and families to discuss these decisions. To ensure that these tools are effective, usable, and understandable, studies are needed to identify patients', families', and providers' decision-making needs and optimal design strategies for a web-based patient decision aid.
\end{abstract}

Objective: Following the international guidelines for the development of a web-based patient decision aid, the objectives of this study are to engage potential users to guide development; review the existing literature and available tools; assess users' decision-making experiences, needs, and design recommendations; and identify shared decision-making approaches to address each need.

Methods: This study used the decisional needs assessment approach, which included creating a stakeholder advisory panel, mapping decision pathways, conducting an environmental scan of existing materials, and administering a decisional needs assessment questionnaire. Thematic analyses identified current decision-making pathways, unmet decision-making needs, and decision support strategies for meeting each need.

Results: The stakeholders reported wide heterogeneity in decision timing and pathways. Relevant existing materials included 2 systematic reviews, 9 additional papers, and multiple educational websites, but none of these met the criteria for a patient decision aid. Patients and family members $(n=54)$ emphasized the need for plain language $(46 / 54,85 \%)$, shared decision making $(45 / 54,83 \%)$, and help with family discussions $(39 / 54,72 \%)$. Additional needs included information about uncertainty, lived experience, and costs. Providers $(n=10)$ reported needing interventions that address misinformation $(9 / 10,90 \%)$, foster realistic 
expectations $(9 / 10,90 \%)$, and address mistrust in clinical trials $(5 / 10,50 \%)$. Additional needs included provider tools that support shared decision making. Both groups recommended designing a web-based patient decision aid that can be tailored to (64/64, $100 \%)$ and delivered on a hospital website $(53 / 64,83 \%)$, focuses on quality of life $(45 / 64,70 \%)$, and provides step-by-step guidance $(43 / 64,67 \%)$. The study team identified best practices to meet each need, which are presented in the proposed decision support design guide.

Conclusions: Patients, families, and providers report multifaceted decision support needs during the chronic phase of cancer. Web-based patient decision aids that provide tailored support over time and explicitly address uncertainty, quality of life, realistic expectations, and effects on families are needed.

(JMIR Form Res 2021;5(7):e27484) doi: 10.2196/27484

\section{KEYWORDS}

patient decision aids; decision support techniques; oncology; medullary thyroid cancer; targeted therapy; clinical trial; mobile phone

\section{Introduction}

\section{Background}

As diagnoses and treatments continue to improve, chronic cancer is increasingly recognized as a unique phase in the cancer care continuum. During this time, many patients face difficult decisions such as whether to try novel therapeutics emerging on the market, whether to enroll in clinical trials, and when to stop treatment. New medicines offer hope but may provide only limited efficacy in select groups, have significant risks of side effects, or involve high out-of-pocket costs for the family. Many clinical trials cover the costs of treatment but involve accepting unknown potential benefits and risks. For some patients, even successful therapeutic effects do not last, and a decision needs to be made about whether to switch therapies or stop treatment. These decisions are classified as preference-sensitive because they involve 2 or more medically relevant options, uncertain benefits, notable risks, and variation in how patients and families value the potential process and outcomes [1].

A prime example is medullary thyroid carcinoma (MTC), a rare thyroid tumor. More than half of patients with MTC develop an advanced or chronic disease and live for years to decades with slowly progressing, often terminal cancer [2,3]. The US Food and Drug Administration approved 3 oral targeted therapies-vandetanib, cabozantinib, and selpercatinib-for the treatment of progressive MTC. Large phase 3 trials comparing vandetanib and cabozantinib with placebos showed improved progression-free survival; however, improvement in overall survival was only observed in small select groups $[4,5]$. These drugs are costly (US \$200-US \$600 per day) and can cause significant diarrhea, weight loss, hypertension, hypertensive crises, profound fatigue, or death $[4,6]$. Selpercatinib has been recently approved for a subset of patients and has been reported to be well tolerated with fewer side effects; however, overall survival benefits have not been shown [7]. Several clinical trials are ongoing; however, patients must be willing to accept randomization and unknown side effects. When discussing a new targeted therapy or clinical trial, it is also important to clarify the conditions under which patients would want to switch or end treatment. These decisions are often revisited iteratively over months or years, with much of patients' deliberations occurring between clinical consultations. Hence, providers have expressed interest in web-based approaches to helping patients and families learn about and prepare to discuss these preference-sensitive decisions [8].

In preference-sensitive care, the best decision involves integrating medical evidence and informed patient preferences. Shared decision-making interventions such as decision coaching and patient decision aids are the gold standard for optimal preference-sensitive care [9-11]. Decision coaching involves semistructured discussion to ensure that patients are well informed, have realistic expectations, are clear about their decision-making values, and have appropriate resources and support to implement the mutually agreed upon choice [12]. Patient decision aids are tools that provide up-to-date, balanced evidence about the options and activities to promote preparation for decision making, values clarification, communication, and engagement [13]. Patient decision aids may be delivered before, during, or between consultations. Multiple Cochrane Collaboration systematic reviews report that patient decision aids help patients become well informed, form more realistic expectations, clarify which risks and benefits matter most to them, and prepare for discussing these decisions with their clinical teams [13-15]. Decision counseling and patient decision aids also address patients' decisional conflict, a state of anxiety that blocks taking action [16]. Previous studies have reported that for each point increase on the 0-100 Decisional Conflict Scale, patients were 23 times more likely to delay their decision, 59 times more likely to change their mind, 5 times more likely to express decision regret, and $19 \%$ more likely to blame doctors for bad outcomes [17].

\section{Objectives}

The International Patient Decision Aid Standards Collaboration provides guidelines for evidence-based systematic development of patient decision aids [18], including reviewing the literature for up-to-date clinical information, assessing the quality and relevance of any existing tools, and conducting a formal decisional needs assessment to identify high-priority decision-making needs. The guidelines chapter, Delivering Decision Aids Using the Internet [19], also recommends a user-centered design process to ensure that the tools are accessible, usable, and meaningful. The long-term goal of this research program is to develop patient- and provider-facing decision support tools for chronic cancer. As a first step, the objectives of this study are to (1) engage users in a stakeholder advisory panel to guide development; (2) review the existing 
literature and available tools; (3) assess the decision-making experiences, needs, and recommendations of patients with MTC, family members, and providers; and (4) identify shared decision-making approaches to address each need.

\section{Methods}

\section{Conceptual Framework}

This initial study (part of a larger trial; NCT03892993) followed the multidisciplinary decisional needs assessment approach outlined by the patient decision aid development guidelines $[18,19]$. One of the key theoretical models underlying this approach is the Ottawa Decision Support Framework [16,20], which has been used to develop decision support interventions in more than 100 studies across 18 countries. This framework applies behavioral, cognitive, and economic decision theories [21-24] to preference-sensitive health care decisions. For example, it postulates several modifiable decision-making needs such as lack of awareness, knowledge, clarity, or support that can be addressed to ensure a high-quality decision-making process (Figure 1).

Figure 1. The Ottawa Decision Support Framework. *Inadequate support and resources to make/implement the decision include: information inadequacy/overload; inadequate perceptions of others' views/practices; social pressure; difficult decisional roles; inadequate experience; self-efficacy, motivation, skills; inadequate emotional support, advice, instrumental help; and inadequate financial assistance, health/social services. Copyright 2019, Ottawa Hospital Research Institute [16,20].

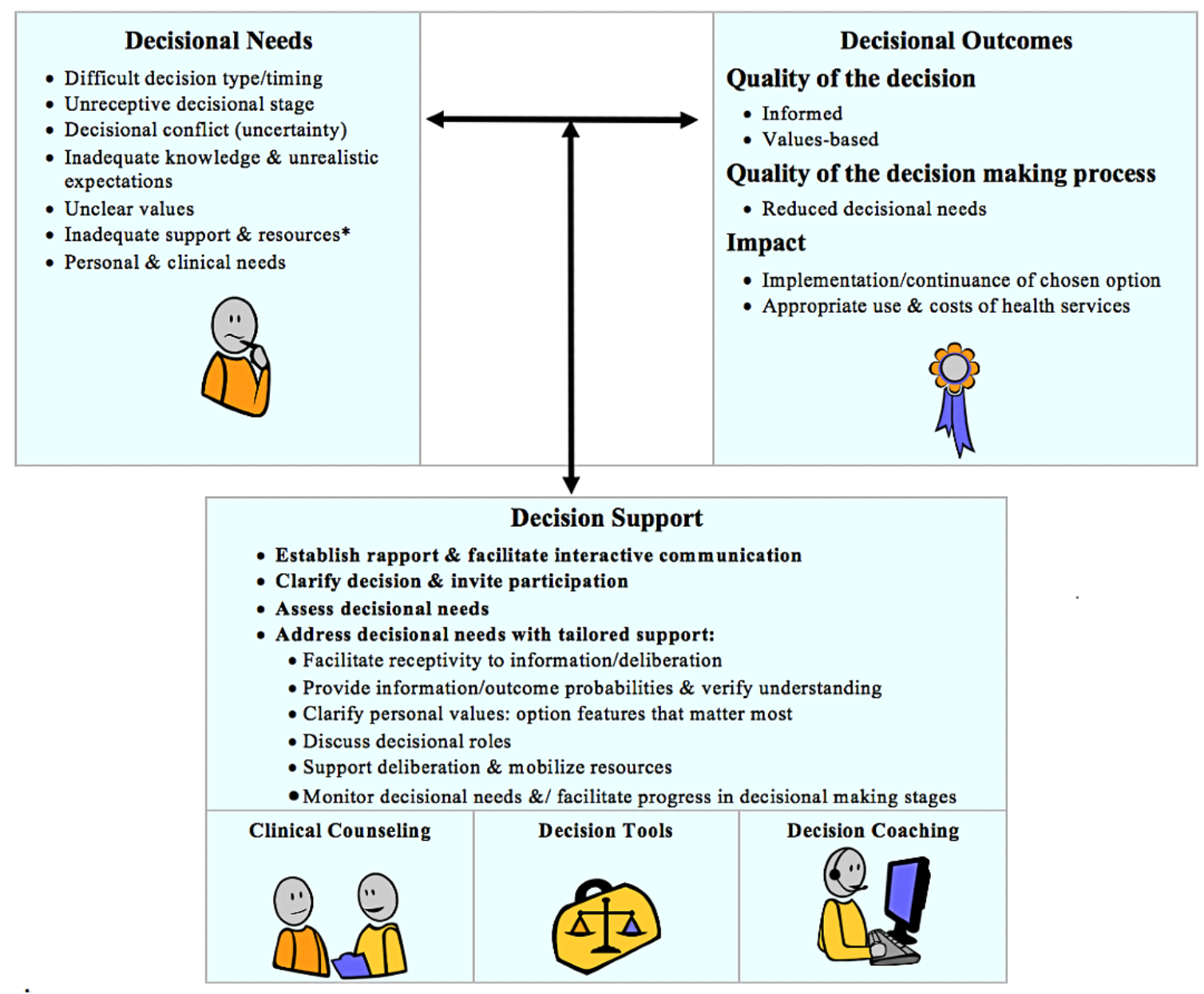

To support rigorous systematic development, this framework was operationalized in 1999 as the Decisional Needs Assessment in Populations [25]. This approach has been used across a wide variety of clinical contexts to assess patients', families', providers', and community members' decision-making experiences, processes, unmet needs, and recommendations for designing meaningful, understandable, and feasible tools [18,25-29]. It involves a series of steps using mixed methods with an emphasis on user-centered design and practical thematic analysis focused on unmet decision-making needs.

\section{Procedures}

\section{Overview}

Following the guidelines for systematic development [18] (Figure 2) and delivery using the internet [19], this study proceeded in 4 steps: (1) engaging a stakeholder advisory panel, (2) reviewing existing literature and tools, (3) administering a decisional needs assessment questionnaire, and (4) developing a decision support design guide to inform the future design of a patient decision aid. The institutional review board of the University of Texas MD Anderson Cancer Center provided ethical review and approval. 
Figure 2. The International Patient Decision Aid Standards Collaboration model for the systematic development of a patient decision aid [18].

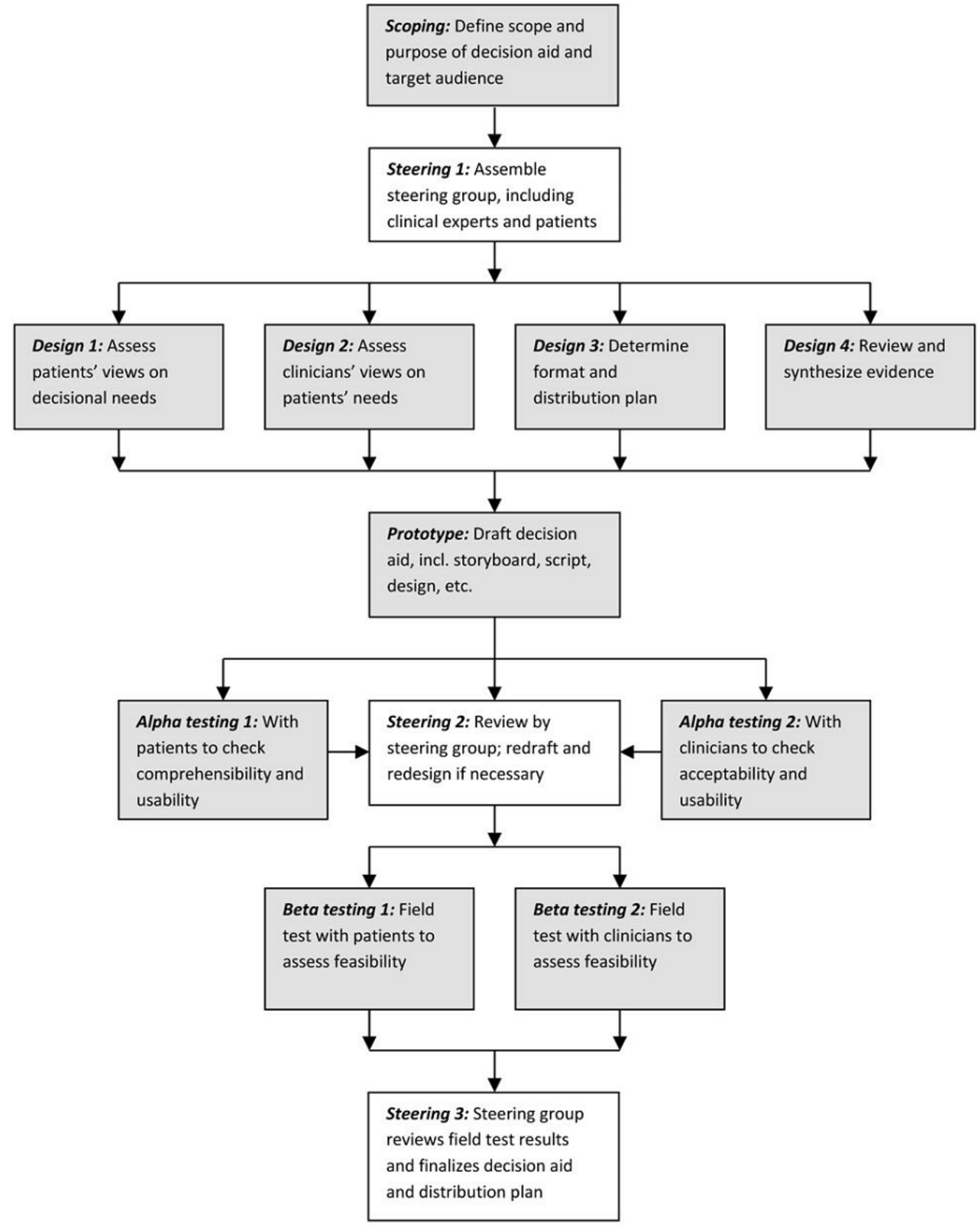

\section{Engaging Users in a Stakeholder Advisory Panel}

To guide the overarching program of research, the study team purposefully invited a diverse group of potential users and key stakeholders, including patients, family members, surgeons, oncologists, and advanced practice providers. Advisory panel members were not participants but partners in the research process who provided guidance on the study methods, proposed questionnaire, potential sources, data interpretations, and the final design guide. The advisory panel meets at least twice per year to discuss the overarching program of research and was engaged in 2 study planning calls and multiple calls and emails as needed to review, edit, and approve study documents, results, interpretations, and this manuscript. Notably, they proposed that the project scope includes both targeted therapies and clinical trials as well as recommendations for a web-based patient decision aid to deliver timely information to patients living in the community. 


\section{Review of Existing Literature and Tools}

A total of 2 reviews of MTCs had been completed in 2016 [30,31]. Therefore, a scoping review [32] was conducted to identify newer publications, and an environmental scan approach [33] was used to identify and assess the quality of existing materials. First, the research team members searched Web of Science, PubMed, and Google Scholar for advanced medullary thyroid carcinoma, decision support, patient decision aid, vandetanib, cabozantinib, surveillance, and clinical trial participation. Next, they used Web of Science to conduct a 1-generation forward and backward citation analysis of the references of the 2 systematic reviews and the papers that referenced the systematic reviews. Finally, the team conducted a gray literature search [34], which involved reviewing relevant websites, brochures, drug labels, and infographics using Google Scholar; web-based patient decision aid libraries; and relevant clinical, advocacy, and survivor support group websites. All reviews were conducted in English, included all time frames and countries, excluded advertisements, and retained only the most recent version of the edited documents or websites.

\section{Decisional Needs Assessment}

The decisional needs assessment questionnaire [25] includes 10 open-ended items assessing respondents' previous experience, decision-making needs, and recommendations for the design of a decision support intervention such as a web-based patient decision aid. We tailored the questionnaire for patients, family members, and providers (eg, "Which of the following decisions [have you considered/have you discussed with your loved one/have you discussed with patients]?"). Patients and family members also responded to 14 items assessing their characteristics. To inform future implementation, providers responded to 2 questions about care pathways. The stakeholder advisory panel and institutional review board reviewed, revised, and approved the questionnaire.

The participants were English-speaking adult patients with MTC, informal caregivers or family members (on their own or with a patient or survivor), and clinicians who treat patients with MTC. The research coordinator recruited eligible patients and family members from the MTC Registry, which includes more than 1500 individuals from 20 states and 6 countries. The study team purposefully recruited patients across the disease spectrum, excluding individuals for whom participation could have caused distress (eg, recently diagnosed or bereaved). The provider participants included endocrinologists, medical oncologists, and surgeons purposefully recruited for their significant expertise and diversity of perspectives. All participants provided informed consent.

Members of the MTC Registry are active on the web and well known to each other and to MTC providers; therefore, additional attention was given to ensuring confidentiality while maximizing access. The research coordinator called each individual and offered an informational email that explained the purpose of, and process for, participating, including the opportunity to respond confidentially and securely on the web (or on paper or by phone, if requested). The email provided the link to a closed web-based questionnaire hosted on REDCap (Research Electronic Data Capture; Vanderbilt University) version 9.1.0
(May 31, 2019) [35]. A total of 2 reminder emails were sent to the nonresponders. All participants completed the questionnaire between May and September 2019. Patients and family members received a US \$10 gift card after participating.

\section{Statistical Analysis}

This exploratory study was not designed to test a hypothesis or generate a theory. Sample sizes were based on the international guidelines and were consistent with previous studies [18,19,28,36-39]. For the questionnaire, the research team used descriptive statistics to summarize quantitative responses and semantic, critical realist thematic analyses [40] to analyze qualitative responses. Beginning with a deductive approach, one author (ASH) hand-coded responses using core concepts from the Ottawa Decision Support Framework [16] (eg, uncertainty and need for information) and clinical literature (eg, side effects and costs). If a new concept arose in 2 or more responses, a new code was proposed, reviewed by a second author (DZS), and used to recode previous records. Conflicts and questions were discussed by 2 authors (EGG and MIH). The full research team met and reviewed the coding and findings twice and then presented all results and findings to the advisory panel to confirm meaningful interpretation and contextualization.

\section{Decision Support Design Guide}

The purpose of a decision support design guide is to identify top-priority design needs (ie, clinical content, decision support activities, graphics, delivery etc) and to propose design solutions to address each need. Consistent with the conceptual framework, the research team organized the needs according to the modifiable factors that contribute to high decisional conflict (ie, feeling uninformed, unclear, unsupported, uncertain, and ineffective) [16] and added a delivery or accessibility category focusing on web-based delivery. Responses were retained if they were top rated or most endorsed across both groups. To identify best practices in decision support and patient decision aid design, the research team consulted the International Patient Decision Aid Standards chapters [12,19,41-46], the Cochrane Collaboration reviews [13,14], selected decision support experts, and the advisory panel. The team aligned the best practices parallel to each need to create a decision support design guide.

\section{Results}

\section{Engaging Users in a Stakeholder Advisory Panel}

The stakeholder advisory panel consisted of 4 patients and family members, 2 oncologic endocrinologists, 1 head and neck surgeon, and 1 advanced practice provider. Their experience and diverse perspectives complemented the expertise of the research team, which included a surgical oncologist, an oncologic endocrinologist, a decision scientist, and a trained research assistant. The advisory panel participated meaningfully in all aspects of the study, from the protocol design to writing this manuscript.

\section{Review of Existing Literature and Tools}

In addition to the previous 2 systematic reviews [30,31], the scoping review and citation analysis identified 9 papers specific to decision making for MTC [3,47-53]. Two papers focused on 
improving diagnosis and staging, 6 papers reported studies of targeted therapeutics, and the remaining paper provided updated clinical practice guidelines. No studies on patient decision aids for starting or stopping targeted therapies were identified. A total of 3 studies of patient decision aids for clinical trial enrollment exist in other contexts [54-57], along with a conceptual framework for development [58]. The environmental scan and gray literature search identified 56 blogs, websites, and posts by clinical and advocacy groups. Review of these webpages confirmed that patients were asking about targeted therapy and clinical trial enrollment decisions; however, no patient decision aid for MTC was identified.

\section{Decisional Needs Assessment}

\section{Participant Characteristics}

The research team invited 106 patients, family members, and providers. A total of 74 individuals responded, and 64 (87\%) individuals completed the questionnaire, including 46 (72\%) patients, $10(16 \%)$ family members, and $10(16 \%)$ providers.
Table 1 summarizes the respondents' characteristics. In addition, $46 \%(25 / 54)$ of patients and family members received surgery and care at both the study site and outside institutions. Notably, the respondents included individuals who had recently undergone a secondary surgery or focal treatment, individuals with indolent disease who may face these decisions in the future, and individuals experiencing an advanced stage of disease treated with at least one systemic therapy agent. Many providers $(6 / 10,60 \%)$ reported being attending physicians who saw 30-50 patients with MTC per year.

The following paragraphs summarize participants' responses to the 3 sections of the questionnaire assessing (1) previous decision-making experiences, (2) decision support needs, and (3) recommendations for designing a decision support tool such as a web-based patient decision aid. To protect individuals' privacy, patient and family member responses have been combined, identifying information has been redacted in the quotes, and results from fewer than 5 patients and family members are reported but not quantified. 
Table 1. Participants' characteristics $(\mathrm{N}=64)$.

\begin{tabular}{|c|c|c|}
\hline Characteristics & Patients and family members ${ }^{\mathrm{a}}(\mathrm{n}=54)$ & Providers $(n=10)$ \\
\hline $\begin{array}{l}\text { Number of years of treating or being with patients with medullary thyroid carcinoma, } \\
\text { median (minimum, maximum) }\end{array}$ & $4.5(<1,24)$ & $13(5,25)$ \\
\hline \multicolumn{3}{|l|}{ Location of cancer care or clinical practice, $\mathbf{n}(\%)^{\mathbf{b}}$} \\
\hline MD Anderson Cancer Center & $44(95)$ & $1(10)$ \\
\hline Another institution & $27(56)$ & $9(90)$ \\
\hline \multicolumn{3}{|l|}{ Experience with medullary thyroid carcinoma, $n(\%)^{b}$} \\
\hline Patient with medullary thyroid cancer or survivor & $46(85)$ & $-^{c}$ \\
\hline Caregiver or family member & $10(19)$ & $-^{c}$ \\
\hline Medical oncologist & $-^{c}$ & $5(50)$ \\
\hline Endocrinologist & 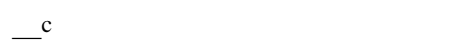 & $4(40)$ \\
\hline Surgeon & 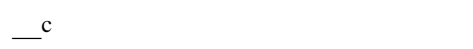 & $1(10)$ \\
\hline Age (years), median (minimum, maximum) & $52(21,80)$ & $46(40,60)$ \\
\hline Female sex, n (\%) & $30(56)$ & $2(20)$ \\
\hline \multicolumn{3}{|l|}{ Race, $\mathbf{n}(\%)^{\mathbf{b}}$} \\
\hline White & $46(85)$ & $7(70)$ \\
\hline Other & $8(15)$ & $3(30)$ \\
\hline Hispanic or Latino/Latina, $\mathrm{n}(\%)$ & $7(13)$ & $0(0)$ \\
\hline \multicolumn{3}{|l|}{ Education, n (\%) } \\
\hline Some college, associate's or technical degree & $14(26)$ & $-^{\mathrm{c}}$ \\
\hline Bachelor's degree & $25(46)$ & $-^{c}$ \\
\hline Graduate degree & $11(20)$ & - $^{\mathrm{c}}$ \\
\hline \multicolumn{3}{|l|}{ Religion, $\mathbf{n}(\%)^{\mathbf{b}}$} \\
\hline Atheism or agnosticism & $5(9)$ & $-^{\mathrm{c}}$ \\
\hline Christianity & $46(85)$ & $-^{c}$ \\
\hline \multicolumn{3}{|l|}{ Health insurance, $\mathbf{n}(\%)^{b}$} \\
\hline Private insurance & $49(91)$ & - $^{\mathrm{c}}$ \\
\hline Medicare or Medicaid & $17(32)$ & $-^{\mathrm{c}}$ \\
\hline \multicolumn{3}{|l|}{ Annual household income (US \$), n (\%) } \\
\hline$<50,000$ & $12(22)$ & $-^{c}$ \\
\hline $50,001-100,000$ & $12(22)$ & $-^{\mathrm{c}}$ \\
\hline$>100,000$ & $30(56)$ & $ـ^{c}$ \\
\hline
\end{tabular}

${ }^{\text {a}}$ To protect patients' privacy, cells with $<5$ responses have not been reported; therefore, not all sections total $100 \%$.

${ }^{\mathrm{b}}$ Participants could select more than 1 response.

${ }^{\mathrm{c}}$ Not assessed in this study group.

\section{Patient and Family Member Perspectives}

Of the 54, $20(37 \%)$ of patients and family members reported making decisions about whether to start a new targeted therapy drug, $24(44 \%)$ had deliberated about whether to enroll in a clinical trial, and $9(16 \%)$ had chosen to stop a therapy. Other responses included whether to take or increase synthetic thyroid hormone, undergo radiation therapy, or undergo surgery with the possibility of losing their voice. A few patients focused on personal decisions such as when to disclose their diagnosis, discuss cascade genetic testing, or inform their family about progression. One person highlighted the decision to accept that 
they had terminal cancer. Others described logistical decisions such as whether to travel for second opinions, treatment, or surgery:

\section{Choosing doctors \& treatment options to best suit my specific needs is difficult because they're few and far between. There are different types of this rare cancer (inherited and sporadic) and...different gene mutations...which ultimately contribute to compartmentalizing and/or reducing treatment options and adversely impacting [one's] specific needs. [Patient] \\ Where to get help? Local endocrinologists and surgeons had little to no experience with MTC and even their comments were unsettling. Is there a benefit to traveling for treatment? [Patient]}

Most of the patients $(31 / 44,72 \%)$ reported worry as a primary barrier, including significant concern regarding how each option would affect their family financially, emotionally, and in caregiving burden. Some patients $(12 / 54,22 \%)$ reported feeling rushed or pressured (by their doctor, family, or insurance company) or worried about disappointing their doctor (10/54, $19 \%$ ). A few patients reported challenges with trust and communication:

\section{I had to decide if I wanted to fight my initial endocrinologist about having genetic testing. He told me it was very expensive and since my children were adopted it wasn't critical. When I asked about my siblings, he shrugged. [Patient]}

Both patients and family members $(16 / 54,30 \%)$ focused on the need for help dealing with uncertainty, clarifying risks, and weighing future effects on quality of life. Some participants $(12 / 54,22 \%)$ reported information barriers such as difficulty finding trustworthy information or frustration over finding conflicting information. A few participants noted that they needed time to process information and to connect with survivors to discuss the lived experience. Notably, most patients $(45 / 54,83 \%)$ and family preferred "discussing treatment options and my preferences with my providers, then making the decisions together." Only a few wanted to make the decision themselves $(6 / 54,11 \%)$ or have the doctor make the decisions $(3 / 54,6 \%)$ :

[We] have small children...[so we] had to weigh in the travel and cost for our family. [Caregiver or family member]

[I] was not allowed time to gain knowledge of MTC. Also, I did not seek a second opinion which would have been valuable. [Patient]

Table 2 summarizes patients' and family members' ratings of possible features for a decision support tool. Overall, most of the patients and family members recommended using plain language and providing a step-by-step guide, example questions, charts, and a printable summary. Other recommendations included providing a glossary, responses to frequently asked questions, question-prompt list, tips for talking with employers, guidelines on how to select a provider, and activities to elicit and clarify what is most important in these decisions (eg, travel costs, financial considerations, and timing):

\section{Keep the language simple. The video we watched for [a previous clinical trial] was very informative. We followed it just fine, but my thoughts drifted to those that might not have a high education level, how well would they comprehend? [Caregiver or family member]}

Keep a library of historical real Questions \& Answers made by people. [Patient]

Mental health information-particularly aimed at grief and how to include children. Explain mortality rates in lay person terms. [Patient]

Table 2. Patients' and family members' recommendations for a decision support tool $(\mathrm{n}=54)$.

\begin{tabular}{ll}
\hline Recommendations for a patient decision aid & Patients and family members, $\mathrm{n}(\%)$ \\
\hline Explain each treatment option in plain language & $44(82)$ \\
A step-by-step guide to walk you through considering the decision & $36(67)$ \\
Example questions to ask the doctor & $32(59)$ \\
Charts comparing options side by side & $30(56)$ \\
Printable summary of your information at the end & $28(52)$ \\
Stories from other patients or families about what each option was like & $27(50)$ \\
A glossary of the medical terms & $27(50)$ \\
Keep it simple & $26(48)$ \\
Stories from other patients or families about how they made these decisions & $25(46)$ \\
Graphics that illustrate the risks (eg, 8 of 10,000 people) & $25(46)$ \\
Activities to help you sort out what is most important to you personally & $16(30)$ \\
A place to write down your questions for the doctor & $14(26)$ \\
Other & $6(11)$ \\
\hline
\end{tabular}


Regarding the amount of information, a slight majority (32/54, $59 \%$ ) reported wanting "the key facts and lots of details about all of the options," but others preferred "the key facts, plus detail about the options I am interested in" (12/54, 22\%) or "the key facts about each of the treatment options" (10/54, 19\%). A few participants commented that they particularly wanted more information for these decisions because of the potential long-term effects on quality of life and on their families. Notably, a few participants requested information comparing clinical trials and information comparing novel therapeutics:

\section{A simple pros and cons list for each clinical trial...or, a chart where you can see each drug side-by-side. [Patient]}

Regarding preferred mediums, most of the patients and family members recommended a worksheet that walks them through the decision(s) $(39 / 54,73 \%)$, an interactive website $(35 / 54$, $66 \%$ ), a 1-page printable summary $(34 / 54,64 \%)$, or video (30/54, 57\%). Most of the participants recommended multiple delivery routes, including the hospital website $(45 / 54,83 \%)$, personal email $(37 / 54,57 \%)$, smartphone app $(25 / 54,46 \%)$, paper copies at the doctor's office $(19 / 54,35 \%)$, or mail (13/54, $24 \%$ ). A few individuals recommended sending the worksheet through the patient portal, providing a link in the annual guidelines, or making it available on social media cancer support groups, peer-to-peer support groups, and patient advocacy sites.

\section{Provider Perspectives}

Regarding current experiences, all providers reported that their care pathway involves treatment by an endocrinologist until progression occurs, followed by referral to a medical oncologist. In total, $70 \%(7 / 10)$ of providers recommended introducing these decisions early on, including at the initial visit. In total, $20 \%(2 / 10)$ of providers recommended waiting until the patient developed distant disease:

[Targeted therapy should be discussed] as soon as distant metastases are identified. If they are small distant mets, then it is a brief mention that systemic therapy options are available in the future. As the mets get bigger or if they are progressing, then more detailed discussions ensue. [Endocrinologist]

At the initial visit, I provide a comprehensive picture of their disease management, the palliative nature of therapy, the role of surveillance, what guides the decision to treat, and what the treatment options are (standard and experimental). [Medical oncologist]

Regarding clinical trials, the providers reported engaging in discussions at least once a week $(3 / 10,30 \%)$, once a month $(4 / 10,40 \%)$, or a few times a year $(2 / 10,20 \%)$. Most of the providers $(7 / 10,70 \%)$ felt that it was their role to initiate these conversations with patients; others $(3 / 10,30 \%)$ felt that it could be introduced by the study team. In total, $40 \%$ (4/10) of providers reported that patients initiated these decisions approximately $50 \%$ of the time or more:

The best quality discussion happens over several visits...more as a continuing conversation, rather than a sudden surprise discussion that it is time to start systemic therapy tomorrow. This gives patients time to think about the information, involve family members, do their own research, and come prepared with better questions. [Endocrinologist]

The providers reported moderate satisfaction with these discussions (10-point scale score: mean 7.5, SD 2.1; minimum=2, maximum=10). Their descriptions of the "best outcome of this conversation" were that patients understood the key information $(6 / 10,60 \%)$, including that trials are experimental, and that they interacted or asked questions $(6 / 10$, $60 \%$ ) and stated that the decision aligned with goals of care $(4 / 10,40 \%)$ :

Success is when a patient and his/her family feel like they have a good understanding of the risks/benefits of their decision and are comfortable with the path we choose together. [Medical oncologist]

Success is they understand that clinical trials are experimental, we don't know if they are better than standard of care, and the risks may not be completely known. [Endocrinologist]

When discussing targeted therapies, the providers reported needing interventions that address preconceived notions $(5 / 10$, $50 \%)$, misinformation $(4 / 10,40 \%)$, and time constraints $(4 / 10$, $40 \%)$. A few described situations in which patients were informed that there is no cure, but they continued to believe that a cure may still be achievable. They also discussed 2 effects of misinformation and preconceived notions: (1) patients assuming that the side effects are negligible and not considering quality of life or (2) patients assuming the degree of side effects to be so harmful that they will not consider a certain therapy. Other barriers included lack of visual aids, poor retention, difficulties clarifying goals of care, fear and logistical challenges related to clinic flow, paucity of multidisciplinary approaches, and insurance coverage:
[Barriers include] preconceived notions from patients that approved therapies are too toxic and not efficacious; some patients want to dictate the way they should be treated. [Endocrinologist]
The limitations imposed by busy clinics and limited time with patients is the biggest hindrance. These are complicated issues that require time with the patient to have a comprehensive discussion that is well-received with the patient. [Medical oncologist]

When discussing decisions about clinical trials, most of the providers $(9 / 10,90 \%)$ also described situations in which patients stated unrealistic goals, overly optimistic assumptions, or beliefs that the trial would be curative. However, half of the providers $(5 / 10,50 \%)$ also discussed conversations in which patients distrusted pharmaceutical companies and did not want to be a "guinea pig." Other barriers included lack of visual aids, concerns about randomization, worry about the unknown risks of side effects, and potential logistical challenges or costs:

[Patients believe] that we are just experimenting on them and that we have no idea whether it will work...there is a general mistrust of drug companies. [Endocrinologist] 
[Patients tell me] "I am a guinea pig," or [they are] overly optimistic that the trial drug will help them [and have few side-effects]. [Endocrinologist]

The providers recommended a variety of approaches to designing a web-based patient decision aid. All providers (10/10, $100 \%$ ) endorsed the need to include both decisions (targeted therapies and clinical trials), and most (7/10, 70\%) endorsed having the ability to tailor or separate the decisions. Table 3 summarizes their ratings of the possible formats. Other responses included purposefully designing the patient decision aid for repeated discussions over time; face-to-face meetings with a midlevel provider to discuss side effects; and 1-page summaries of the disease, therapies, and trials:

Individualization is key. [Medical oncologist]

In the absence of a curative systemic therapy, I think

I would use a decision aid that incorporates standard of care and clinical trials. [Endocrinologist]

Table 3. Perceptions regarding potential decision support tools ( $\mathrm{N}=64)$.

\begin{tabular}{|c|c|c|}
\hline How helpful would the following tools be? & $\begin{array}{l}\text { Patients and family } \\
\text { members }(\mathrm{n}=54)\end{array}$ & Providers $(\mathrm{n}=10)$ \\
\hline \multicolumn{3}{|l|}{ Patient-facing tools, $n(\%)$} \\
\hline A 1-page comparison chart of the treatment options you can use in consultation & $34(64)$ & $9(90)$ \\
\hline A brochure or video patients can be given before their appointment & $30(57)$ & $8(80)$ \\
\hline $\begin{array}{l}\text { A worksheet about preferences and values they complete that you can add to their electronic health } \\
\text { record }\end{array}$ & $39(74)$ & $7(70)$ \\
\hline A page on your institutional website & $35(66)$ & $6(60)$ \\
\hline A face to face meeting with a nurse to talk about side effects & $0(0)$ & $6(60)$ \\
\hline Other & $8(15)$ & $7(70)$ \\
\hline \multicolumn{3}{|l|}{ Provider-facing tools, $\mathrm{n}(\%)$} \\
\hline A brief training seminar on the current evidence & $-{ }^{\mathrm{a}}$ & $7(70)$ \\
\hline A brief training seminar on decision coaching as a clinical skill & $-{ }^{\mathrm{a}}$ & $7(70)$ \\
\hline $\begin{array}{l}\text { A collaborative meeting between departments to discuss the upstream/downstream impacts of these } \\
\text { decisions }\end{array}$ & $-^{\mathrm{a}}$ & $7(70)$ \\
\hline A study of the patients' reported experience & $-^{\mathrm{a}}$ & $7(70)$ \\
\hline Other & $-{ }^{\mathrm{a}}$ & $0(0)$ \\
\hline
\end{tabular}

${ }^{\mathrm{a}}$ Not assessed in this study group.

In terms of the key facts that should be conveyed, most of the providers $(7 / 10,70 \%)$ focused on quality of life and repeating that targeted therapies may not prolong survival. Some also focused on balanced discussion, lack of known probabilities, acknowledging that experimental therapy may be better tolerated, emphasizing that goals of care change over time, and describing co-pays. A few providers cautioned that the decision aid should advise patients to make sure that their expectations, both expressed and implied, are realistic before enrolling in a clinical trial. One provider also recommended explicitly addressing the concept of altruistic volunteering:

\section{A tutorial on the role of clinical trials in drug development and patient care to establish general background before a discussion would be helpful. [Medical oncologist]}

The providers recommended introducing clinical trials early on or during the first visit $(4 / 10,40 \%)$, at the same time as standard therapies $(3 / 10,30 \%)$, or at all stages $(3 / 10,30 \%)$. A few providers recommended waiting until standard therapy failed, before surgery, or when a novel therapy has compelling clinical data. Several providers brought up improving the overall decision-making process, including developing better patient education materials $(3 / 10,30 \%)$ and initiating multidisciplinary conversations earlier $(3 / 10,30 \%)$. Other recommendations included getting clarity about expectations, verbally encouraging patients to communicate side effects, and planning additional time for these conversations. They also recommended that the conversation be led by a clinician who is experienced in caring for patients with MTC:

\section{[We need] better patient education materials aimed toward patients in their language. [Endocrinologist] \\ [We need] to have MTC patients see knowledgeable medical oncologists earlier in the disease course, so it doesn't feel like a defeat when they're referred to us. [Medical oncologist]}

\section{Decision Support Design Guide}

Figure 3 illustrates the decision support design guide, with the left column listing the top-reported decision support needs and the right column proposing decision support approaches to address each need. A review of the international standards identified several relevant best practices, including explicitly introducing shared decision making, inviting engagement, balanced presentation of pros and cons, addressing uncertainty, 
providing cost ranges, and delivering the patient decision aid on the hospital website with optional paper worksheets. To meet provider needs, strategies include seminars on decision coaching, communication, and behavioral therapy skills (to address anxiety, trust, fear, etc); a consultation tool kit of shared decision-making discussion prompts; responses to frequently asked questions; 1-page summaries of clinical trials; or illustrative material such as icon arrays and side-by-side comparison charts. The advisory panel reviewed and approved the design guide for use in future studies.

Figure 3. Decision support design guide. Left column: top-rated decision support needs from our assessment. Right column: proposed decision support strategies for addressing each need.

\section{Decision Support Design Guide}

\section{Unmet Decision-making Needs}

Feeling Uninformed

- Explanations of therapeutics and clinical trials

- Acknowledge other patient-identified decisions

- Definitions of key terms (non-curative vs. non-progression, targeted therapies)

- Benefits \& risks described in terms of quality of life

- Evidence of lived experience, quality of life, \& costs

Feeling Unclear

- Activities to personalize information, risks, \& costs

- Activities to help clarify goals of care

- Examples of realistic expectations

Feeling Unsupported

- Ways to address worry about how these decisions will affect family financially, emotionally, \& logistically

- Ways to add ress feeling pressured, rushed, or worried about disappointing doctor

- Stories \& opportunities to talk with nurses \& patients

Feeling Uncertain

- Ways to understand and address uncertainty

- Confirmation that decisions may be revisited/changed

- Example questions \& place to write down questions

Feeling Ineffective (at Making a Good Decision)

- Multiple levels of deliberative support and engagement

- Step-by-step decision-making guide

- Printable summary

Accessibility \& Delivery

- Key facts plus optional levels of detail

- Address health literacy

- Available on hospital website, email, phone, \& paper

- Worksheet, interactive website, and/or video

- Available at multiple time points

Provider Preparation \& Resources

- Information about current trials \& shared decision making

- Ability to tailor tools \& discussion (therapies vs. trials)

- Ways to address misinformation, preconceived notions, risks, and trust in clinical trials

- Ways to assess preferences $\&$ document

\section{Proposed Design Strategies}

\section{Clinical Content}

- Scope: starting, stopping, or continuing targeted therapies \& clinical trials, acknowledge other decisions

- Plain language, glossary, hover-over definitions

- Frame in terms of quality of life

- Patient-reported data regarding lived experience, quality of life, \& cost ranges for each option

\section{Values Clarification}

- Side-by-side comparison charts and values clarification exercises, including goals of care

- Explain challenges with affective forecasting \& provide narrative examples

Addressing the Role of Family \& Providers

- Behavioral therapies and conversation sheets (Tips for Family Discussions, Tips for Conflict Resolution)

- Available online to review at home with invitation email from provider

- Decision counseling (trained peers, nurses)

Identify Gaps \& Close the Loop

- Explicitly address uncertainty \& paucity of evidence

- Provide example pathways/timelines

- Question-prompt list \& open areas for notes/questions

Building Shared Decision-making Skills

- Ways to assess preferred role in shared decision-making process

- Introduction to shared decision-making process

- Personal decision-making worksheet (printable)

Format \& Features

- Interactive/self-tailorable tool

- Plain language, glossary, illustrations, \& risk graphics

- Multimedia set of tools (patient decision aid, worksheet, summary sheets for trials, etc.)

- Memorable static URL for revisiting over time; triggered \& standard invitation intervals

Provider Training \& Toolkit

-Webinars on Decision Coaching as a Clinical Skill, behavioral counseling skills, \& clinical trial updates

- Tailorable tool \& consultation toolkits

- Frequently asked questions

- Patient-reported outcome measures integrated into electronic health record 


\section{Discussion}

\section{Principal Findings}

Overall, the results indicate that patients with chronic cancer may have significant unmet decision-making needs, and strong support exists for designing decision support tools regarding novel targeted therapies and clinical trial enrollment. Patients and family members report multiple information and decision support needs, such as needing understandable information, examples of the lived experience, help in personalizing the information, strategies to address worry, step-by-step guidance, and opportunities to revisit decision making over time. In addition, the providers emphasized the need to address misinformation, foster realistic expectations, and address mistrust toward clinical trials. The participants supported the development of a web-based tool that can be delivered across multiple platforms (hospital website and email) and that provides a printable personal summary. The providers also requested tools to support shared decision making in consultation. Although no existing patient decision aid could be identified, clinical content regarding targeted therapies is available, and examples of clinical trial tools exist in other clinical contexts. To support clinicians and designers who wish to develop such a tool, the proposed decision support design guide (Figure 3) illustrates the top-priority needs and best practices in decision support to address each need.

\section{Comparison With Previous Work}

The results of this needs assessment highlighted several constructs, mechanisms, and behaviors that may affect patient decision aid design. Patients and family members reported heterogeneous information-seeking behaviors and deliberative styles. Some preferred "just the key facts" and may have been overwhelmed by too much detail, whereas others sought highly detailed information and side-by-side comparison charts. Some preferred implicit decision support (introducing the concepts of shared decision making but allowing them to manage their deliberative process internally), whereas others specifically requested explicit decision support (providing step-by-step guidance, interactive websites, or worksheets) [19]. These patterns are consistent with those in other studies [19,27] and may be linked to coping strategies such as monitoring (seeking a sense of control by seeking and attending to information) or blunting (seeking a sense of control by limiting information) $[59,60]$. Additional research is needed to explore dynamic designs that assess and address each patient's information-seeking and deliberative styles.

Furthermore, these decisions highlight the challenges of shared decision making in the context of chronic or terminal stages of disease. The Ottawa Decision Support Framework focuses on addressing modifiable constructs to decisional conflict, such as feeling uninformed, unclear, and uncertain [16,17]. When discussing novel therapeutics and clinical trial enrollment, the options for providing evidence to foster certainty may be limited. However, the process of helping patients acclimate to the paucity of information, clarify what matters most (including quality of life), develop shared decision-making skills, and communicate with family and providers may provide important benefits that improve long-term decisional regret.

To our knowledge, this is the first study of MTC decision support needs and recommendations for a patient decision aid $[13,61]$. Previous studies have focused on the quality of patient-facing information. A review of 100 thyroid cancer websites $[62,63]$ reported that most of the websites addressed diagnosis $(92 / 100,92 \%)$ and treatment $(94 / 100,94 \%)$; however, only some $(50 / 100,50 \%)$ were accurate, included source references $(53 / 100,53 \%)$, or were appropriate for a high school education level (2/100, 2\%). A similar study in Germany [48] reported similar heterogeneity in the quality and accessibility of information. One study [50] tested web-based, personalized information and support with individuals with neuroendocrine tumors and found no difference in patients' distress or satisfaction. A recent review of websites for the surgical management of low-risk thyroid cancer [64] reported that few $(19 / 60,32 \%)$ of the websites presented all treatment options, and none of the websites discussed the 2015 guidelines [3].

Since the 2017 review of internet-based patient decision aids [19], several studies have been published that may inform the design of web-based tools [65-72]. Overall, these studies continue to report positive ratings of acceptability, usability, and satisfaction as well as improved knowledge, decisional conflict, decision self-efficacy, preparation for decision making, and satisfaction. Baptista et al [73] reported that web-based patient decision aids improved knowledge and decisional conflict compared with usual care and were comparable with paper-based patient decision aids. Related reviews of computerized decision aids [74,75] report positive outcomes and satisfaction, strong correlations with the quality of development, and improved decision making for tools with features such as content control but poorer decision making when tools included tailoring or patient narratives. These topics continue to be emerging areas of research and can be explored in user design studies.

On the basis of the results of this study, the next steps will include continuing with the systematic development of a patient decision aid (Figure 2) for patients and family members with MTC. Once the review and synthesis of the clinical evidence are complete and we develop the initial prototype with the advisory panel, we will re-engage the participants who consented to be recontacted to iteratively review and revise the drafts. In parallel, we will develop and validate a Decision Quality Index, the gold standard measure of the degree to which patients' decisions are informed and values congruent. With these tools, we can begin to simultaneously assess efficacy and effectiveness as well as explore some of the methodological research questions discussed herein. The ultimate long-term goals of this program of research continue to be to help patients with MTC and their families to make well-informed personal health care decisions, while simultaneously learning from patient-reported data about patients' needs, values, cultural considerations, and informed preferences regarding starting and stopping novel therapeutics and clinical trials. 


\section{Limitations}

Several limitations of this study should be noted. The use of a web-based questionnaire typically limits follow-up; however, respondents are well known in this small and very active community, and most of the patients and family members consented to continued involvement in the iterative design and testing of tools and resources. Most patients received care at a comprehensive care center; however, we included patients across the spectrum of care (newly diagnosed to advanced disease), and responses were received from 19 states. This initial study focused on decisions about therapeutics and clinical trial enrollment; however, needs assessments are needed for the other difficult decisions identified by the respondents.

\section{Conclusions}

Patients with chronic progressive cancers and their families face difficult decisions involving high uncertainty, complex topics, and concerns about potential effects on the family. High-quality patient decision aids are needed that provide information in plain language, explain how to make a decision under uncertainty, incorporate quality of life, address potential effects on family members, and can be revisited over time.

\section{Acknowledgments}

The authors would like to thank the patients and family members of the Medullary Thyroid Cancer Registry of the University of Texas MD Anderson Cancer Center and the University of California, San Francisco. The authors also acknowledge the Shared Decision-Making Collaborative and the Duncan Family Institute for Cancer Prevention and Risk Assessment. The authors also greatly thank and acknowledge the important insight and guidance provided by their stakeholder advisory panel, both the individuals who were able to participate as authors as well as Anne Brinkman, Jennifer Morgenthaler, Dwight Vicks, Lu Harris, and Shari Harris. Editorial support was provided by Bryan Tutt, Editing Services, Research Medical Library, the University of Texas MD Anderson Cancer Center. Financial support for this study was provided by an institutional research grant from the University of Texas MD Anderson Cancer Center. The funding agreement ensured the authors' independence in designing the study, interpreting the data, and writing and publishing this paper.

\section{Conflicts of Interest}

JAS is a member of the Data Monitoring Committee of the Medullary Thyroid Cancer Consortium Registry and is supported by GlaxoSmithKline, Novo Nordisk, Astra Zeneca, and Eli Lilly. She receives institutional research funding from Exelixis and Eli Lilly. MEC is part of the advisory board in Exelixis. All other authors declare that they do not have any real or perceived conflicts of interest.

\section{References}

1. Eddy DM. Clinical decision making: from theory to practice. Rationing by patient choice. J Am Med Assoc 1991 Jan 02;265(1):105-108. [doi: 10.1001/jama.265.1.105] [Medline: 1984107]

2. Roman S, Lin R, Sosa JA. Prognosis of medullary thyroid carcinoma: demographic, clinical, and pathologic predictors of survival in 1252 cases. Cancer 2006 Nov 01;107(9):2134-2142 [FREE Full text] [doi: 10.1002/cncr.22244] [Medline: $\underline{17019736}$ ]

3. Wells SA, Asa SL, Dralle H, Elisei R, Evans DB, Gagel RF, American Thyroid Association Guidelines Task Force on Medullary Thyroid Carcinoma. Revised American Thyroid Association guidelines for the management of medullary thyroid carcinoma. Thyroid 2015 Jun;25(6):567-610 [FREE Full text] [doi: 10.1089/thy.2014.0335] [Medline: 25810047]

4. Wells SA, Robinson BG, Gagel RF, Dralle H, Fagin JA, Santoro M, et al. Vandetanib in patients with locally advanced or metastatic medullary thyroid cancer: a randomized, double-blind phase III trial. J Clin Oncol 2012 Jan 10;30(2):134-141 [FREE Full text] [doi: 10.1200/JCO.2011.35.5040] [Medline: 22025146]

5. Elisei R, Schlumberger MJ, Müller SP, Schöffski P, Brose MS, Shah MH, et al. Cabozantinib in progressive medullary thyroid cancer. J Clin Oncol 2013 Oct 10;31(29):3639-3646 [FREE Full text] [doi: 10.1200/JCO.2012.48.4659] [Medline: 24002501]

6. Frampton JE. Vandetanib: in medullary thyroid cancer. Drugs 2012 Jul 09;72(10):1423-1436. [doi: 10.2165/11209300-000000000-00000] [Medline: 22715896]

7. Wirth LJ, Sherman E, Robinson B, Solomon B, Kang H, Lorch J, et al. Efficacy of selpercatinib in RET-altered thyroid cancers. N Engl J Med 2020 Aug 27;383(9):825-835. [doi: 10.1056/nejmoa2005651]

8. Hoffman AS, Amaku R, Hu M, Grubbs E. How do we meet the multifaceted decision support needs of people with chronic cancer? A survey of medullary thyroid cancer patients', families', and providers' experiences, needs, and preferences when considering novel therapeutics and clinical trials. In: Proceedings of the 42nd Annual North American Meeting of the Society for Medical Decision Making. 2020 Presented at: The 42nd Annual North American Meeting of the Society for Medical Decision Making; October 6, 2020; Virtual Meeting (Sage Publishing).

9. National Standards for the Certification of Patient Decision Aids. Washington, DC: National Quality Forum; Dec 15, 2016:1-19.

10. Oshima Lee E, Emanuel EJ. Shared decision making to improve care and reduce costs. N Engl J Med 2013 Jan 03;368(1):6-8. [doi: 10.1056/NEJMp1209500] [Medline: 23281971] 
11. Poddar U, Brownlee S, Stacey D, Volk RJ, Williams JW, Elwyn G. Patient decision aids: a case for certification at the national level in the United States. J Clin Ethics 2015;26(4):306-311. [Medline: 26752384]

12. Stacey D, Kryworuchko J, Belkora J, Davison BJ, Durand M, Eden KB, et al. Coaching and guidance with patient decision aids: a review of theoretical and empirical evidence. BMC Med Inform Decis Mak 2013 Nov 29;13(S2):1-11. [doi: $10.1186 / 1472-6947-13-s 2-s 11]$

13. Stacey D, Légaré F, Lewis K, Barry MJ, Bennett CL, Eden KB, et al. Decision aids for people facing health treatment or screening decisions. Cochrane Database Syst Rev 2017 Apr 12;4:CD001431 [FREE Full text] [doi: 10.1002/14651858.CD001431.pub5] [Medline: 28402085]

14. Stacey D, Légaré F, Col NF, Bennett CL, Barry MJ, Eden KB, et al. Decision aids for people facing health treatment or screening decisions. Cochrane Database Syst Rev 2014 Jan 28;12(1):CD001431 [FREE Full text] [doi: 10.1002/14651858.CD001431.pub4] [Medline: 24470076]

15. Stacey D, Bennett CL, Barry MJ, Col NF, Eden KB, Holmes-Rovner M, et al. Decision aids for people facing health treatment or screening decisions. Cochrane Database Syst Rev 2011 Oct 05(10):CD001431. [doi: 10.1002/14651858.CD001431.pub3] [Medline: 21975733]

16. O'Connor AM, Tugwell P, Wells GA, Elmslie T, Jolly E, Hollingworth G, et al. A decision aid for women considering hormone therapy after menopause: decision support framework and evaluation. Patient Educ Couns 1998 Mar;33(3):267-279. [doi: 10.1016/s0738-3991(98)00026-3] [Medline: 9731164]

17. O'Connor A. User Manual - Decisional Conflict Scale. Ottawa, ON, Canada: Ottawa Health Research Institute; 1993.

18. Coulter A, Stilwell D, Kryworuchko J, Mullen PD, Ng CJ, van der Weijden T. A systematic development process for patient decision aids. BMC Med Inform Decis Mak 2013;13 Suppl 2:S2 [Accessed June 15, 2021] [FREE Full text] [doi: 10.1186/1472-6947-13-S2-S2] [Medline: 24625093]

19. Hoffman AS, Volk RJ, Saarimaki A, Stirling C, Li LC, Härter M, et al. Delivering patient decision aids on the internet: definitions, theories, current evidence, and emerging research areas. BMC Med Inform Decis Mak 2013;13 Suppl 2:S13 [Accessed June 15, 2021] [FREE Full text] [doi: 10.1186/1472-6947-13-S2-S13] [Medline: 24625064]

20. Stacey D, Murray MA, Légaré F, Sandy D, Menard P, O'Connor A. Ottawa Decision Support Framework, 1999 [revised 2019]. Ottawa Hospital Research Institute. URL: https://decisionaid.ohri.ca/models.html [accessed 2021-07-15]

21. Ajzen I. The theory of planned behavior. Organ Behav Hum Decis Process 1991 Dec;50(2):179-211 [FREE Full text] [doi: 10.1016/0749-5978(91)90020-T]

22. Bandura A. Human agency in social cognitive theory. Am Psychol 1989 Sep;44(9):1175-1184. [doi: 10.1037/0003-066x.44.9.1175] [Medline: 2782727]

23. Elstein AS. Heuristics and biases: selected errors in clinical reasoning. Acad Med 1999 Jul;74(7):791-794. [doi: 10.1097/00001888-199907000-00012] [Medline: 10429587]

24. Kahneman D, Tversky A. Variants of uncertainty. Cognition 1982 Mar;11(2):143-157. [doi: 10.1016/0010-0277(82)90023-3] [Medline: 7198958$]$

25. Jacobsen MJ, O'Connor AM, Stacey D. Decisional Needs Assessment in Populations. Ottawa, ON, Canada: Ottawa Hospital Research Institute; 1999.

26. Hoffman A, Bateman DR, Bartels S, Blandin K, Santulli RB, Lee H, et al. Patient and caregiver needs and preferences for decision support interventions in Alzheimer's disease. Am J Geriatr Psychiatry 2013 Mar;21(3):98-99. [doi: 10.1016/j.jagp.2012.12.130]

27. Hoffman AS. Teaching Diverse Orthopaedic Patient Populations About Deliberative Decision Making Skills: Testing a Design Strategy for Online Patients' Decision Aids. Hanover, NH, USA: Dartmouth College; May 26, 2011:1-288.

28. Woodard TL, Hoffman AS, Covarrubias LA, Holman D, Schover L, Bradford A, et al. The Pathways fertility preservation decision aid website for women with cancer: development and field testing. J Cancer Surviv 2018 Feb 15;12(1):101-114. [doi: 10.1007/s11764-017-0649-5] [Medline: 29034438]

29. Dugas M, Trottier M, Chipenda Dansokho S, Vaisson G, Provencher T, Colquhoun H, et al. Involving members of vulnerable populations in the development of patient decision aids: a mixed methods sequential explanatory study. BMC Med Inform Decis Mak 2017 Jan 19;17(1):12 [Accessed June 15, 2021] [FREE Full text] [doi: 10.1186/s12911-016-0399-8] [Medline: 28103862]

30. Cabanillas ME, McFadden DG, Durante C. Thyroid cancer. Lancet 2016 Dec 03;388(10061):2783-2795. [doi: 10.1016/S0140-6736(16)30172-6] [Medline: 27240885]

31. Kim BH, Kim IJ. Recent updates on the management of medullary thyroid carcinoma. Endocrinol Metab 2016;31(3):392. [doi: 10.3803/enm.2016.31.3.392]

32. Pawliuk C, Brown HL, Widger K, Dewan T, Hermansen A, Grégoire MC, et al. Optimising the process for conducting scoping reviews. BMJ Evid Based Med 2020 Oct 21:A. [doi: 10.1136/bmjebm-2020-111452] [Medline: 33087454]

33. Choo CW. The art of scanning the environment. Bull Am Soc Info Sci Tech 2005 Jan 31;25(3):21-24. [doi: 10.1002/bult.117]

34. Mahood Q, Van Eerd D, Irvin E. Searching for grey literature for systematic reviews: challenges and benefits. Res Synth Methods 2014 Sep;5(3):221-234. [doi: 10.1002/jrsm.1106] [Medline: 26052848]

35. Harris PA, Taylor R, Thielke R, Payne J, Gonzalez N, Conde JG. Research electronic data capture (REDCap)--a metadata-driven methodology and workflow process for providing translational research informatics support. J Biomed 
Inform 2009 Apr;42(2):377-381 [Accessed June 15, 2021] [FREE Full text] [doi: 10.1016/j.jbi.2008.08.010] [Medline: 18929686]

36. Hoffman AS, Llewellyn-Thomas HA, Tosteson AN, O'Connor AM, Volk RJ, Tomek IM, et al. Launching a virtual decision lab: development and field-testing of a web-based patient decision support research platform. BMC Med Inform Decis Mak 2014 Dec 12;14:112 [Accessed June 15, 2021] [FREE Full text] [doi: 10.1186/s12911-014-0112-8] [Medline: 25495552]

37. Hoffman AS, Bateman DR, Ganoe C, Punjasthitkul S, Das AK, Hoffman DB, et al. Development and field testing of a long-term care decision aid website for older adults: engaging patients and caregivers in user-centered design. Gerontologist 2020 Jul 15;60(5):935-946. [doi: 10.1093/geront/gnz141] [Medline: $\underline{31773140]}$

38. Hoffman AS, Cantor SB, Fingeret MC, Housten AJ, Hanson SE, McGee JH, et al. Considering breast reconstruction after mastectomy: a patient decision aid video and workbook. Plast Reconstr Surg Glob Open 2019 Nov;7(11):e2500 [FREE Full text] [doi: 10.1097/GOX.0000000000002500] [Medline: 31942296]

39. De Vito Dabbs A, Myers BA, Mc Curry KR, Dunbar-Jacob J, Hawkins RP, Begey A, et al. User-centered design and interactive health technologies for patients. Comput Inform Nurs 2009;27(3):175-183 [FREE Full text] [doi: 10.1097/NCN.0b013e31819f7c7c] [Medline: 19411947]

40. Braun V, Clarke V. Using thematic analysis in psychology. Qual Res Psychol 2006 Jan;3(2):77-101. [doi: 10.1191/1478088706qp063oa]

41. Joseph-Williams N, Abhyankar P, Boland L, Bravo P, Brenner AT, Brodney S, et al. What works in implementing patient decision aids in routine clinical settings? A rapid realist review and update from the international patient decision aid standards collaboration. Med Decis Making 2020 Dec 15:A [FREE Full text] [doi: 10.1177/0272989X20978208] [Medline: $\underline{33319621]}$

42. Bekker HL, Winterbottom AE, Butow P, Dillard AJ, Feldman-Stewart D, Fowler FJ, et al. Do personal stories make patient decision aids more effective? A critical review of theory and evidence. BMC Med Inform Decis Mak 2013 Nov 29;13(S2):S2. [doi: 10.1186/1472-6947-13-s2-s9]

43. McCaffery KJ, Holmes-Rovner M, Smith SK, Rovner D, Nutbeam D, Clayman ML, et al. Addressing health literacy in patient decision aids. BMC Med Inform Decis Mak 2013;13 Suppl 2:S10 [Accessed June 15, 2021] [FREE Full text] [doi: 10.1186/1472-6947-13-S2-S10] [Medline: 24624970]

44. Feldman-Stewart D, O’Brien MA, Clayman ML, Davison BJ, Jimbo M, Labrecque M, et al. Providing information about options in patient decision aids. BMC Med Inform Decis Mak 2013 Nov 29;13(S2):S2. [doi: 10.1186/1472-6947-13-s2-s4]

45. Fagerlin A, Pignone M, Abhyankar P, Col N, Feldman-Stewart D, Gavaruzzi T, et al. Clarifying values: an updated review. BMC Med Inform Decis Mak 2013;13 Suppl 2:S8 [Accessed June 15, 2021] [FREE Full text] [doi: 10.1186/1472-6947-13-S2-S8] [Medline: 24625261]

46. Montori VM, LeBlanc A, Buchholz A, Stilwell DL, Tsapas A. Basing information on comprehensive, critically appraised, and up-to-date syntheses of the scientific evidence: a quality dimension of the International Patient Decision Aid Standards. BMC Med Inform Decis Mak 2013 Nov 29;13(S2):S5. [doi: 10.1186/1472-6947-13-s2-s5]

47. Arrangoiz R, Cordera F, Caba D, Munoz M, Moreno E, Luque de Leon E. Case report and literature review of medullary thyroid carcinoma. Am J Otolaryngol Head Neck Surg 2018 Nov 21;1(6):1-5. [doi: 10.25107/ajohns-v1-id1026]

48. Kuenzel U, Sindeu T, Schroth S, Huebner J, Herth N. Evaluation of the quality of online information for patients with rare cancers: thyroid cancer. J Cancer Educ 2018 Oct;33(5):960-966. [doi: 10.1007/s13187-017-1173-z] [Medline: 28120139]

49. Rao SN, Cabanillas ME. Navigating systemic therapy in advanced thyroid carcinoma: from standard of care to personalized therapy and beyond. J Endocr Soc 2018 Oct 01;2(10):1109-1130. [doi: 10.1210/js.2018-00180] [Medline: 30250937]

50. de Hosson LD, Bouma G, Stelwagen J, van Essen H, de Bock GH, de Groot DJ, et al. Web-based personalised information and support for patients with a neuroendocrine tumour: randomised controlled trial. Orphanet J Rare Dis 2019 Feb 28;14(1):60 [FREE Full text] [doi: 10.1186/s13023-019-1035-3] [Medline: 30819238]

51. Hadoux J, Schlumberger M. Chemotherapy and tyrosine-kinase inhibitors for medullary thyroid cancer. Best Pract Res Clin Endocrinol Metab 2017 Jun;31(3):335-347. [doi: 10.1016/j.beem.2017.04.009] [Medline: 28911729]

52. Cabanillas ME, Habra MA. Lenvatinib: Role in thyroid cancer and other solid tumors. Cancer Treat Rev 2016 Jan;42:47-55 [FREE Full text] [doi: 10.1016/j.ctrv.2015.11.003] [Medline: 26678514]

53. Schlumberger M, Jarzab B, Cabanillas ME, Robinson B, Pacini F, Ball DW, et al. A phase II trial of the multitargeted tyrosine kinase inhibitor lenvatinib (E7080) in advanced medullary thyroid cancer. Clin Cancer Res 2016 Jan 01;22(1):44-53 [FREE Full text] [doi: 10.1158/1078-0432.CCR-15-1127] [Medline: 26311725]

54. Juraskova I, Butow P, Lopez A, Seccombe M, Coates A, Boyle F, et al. Improving informed consent: pilot of a decision aid for women invited to participate in a breast cancer prevention trial (IBIS-II DCIS). Health Expect 2008 Sep;11(3):252-262. [doi: 10.1111/j.1369-7625.2008.00498.x] [Medline: 18816321]

55. Sundaresan P, Ager B, Turner S, Costa D, Kneebone A, Pearse M, et al. A randomised controlled trial evaluating the utility of a patient decision aid to improve clinical trial (RAVES 08.03) related decision-making. Radiother Oncol 2017 Oct;125(1):124-129 [Accessed June 15, 2021] [FREE Full text] [doi: 10.1016/j.radonc.2017.08.013] [Medline: 28844330]

56. Bhattacharya I, Haviland J, Balasopoulou A, Stones L, Stobart H, Turner L. Abstract P6-12-04: Does the addition of a patient decision aid video reduce decisional conflict in patients considering a de-escalation of radiotherapy trial? Results from the PRIMETIME study. Cancer Res 2020;80(4 Supplement):6-12. [doi: 10.1158/1538-7445.sabcs19-p6-12-04] 
57. Gillies K, Cotton S, Brehaut J, Politi M, Skea Z. Decision aids for people considering taking part in clinical trials. Cochrane Db Syst Rev 2015;11:1-39. [doi: 10.1002/14651858.cd009736.pub2]

58. Gillies K, Campbell MK. Development and evaluation of decision aids for people considering taking part in a clinical trial: a conceptual framework. Trials 2019 Jul 05;20(1):401 [Accessed June 15, 2021] [FREE Full text] [doi: 10.1186/s13063-019-3489-y] [Medline: 31277693]

59. Miller SM. Monitoring versus blunting styles of coping with cancer influence the information patients want and need about their disease. Implications for cancer screening and management. Cancer 1995 Jul 15;76(2):167-177. [doi:

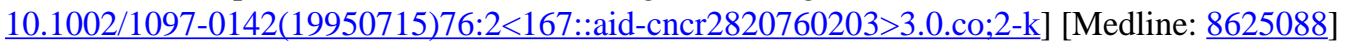

60. Rood JA, Van Zuuren FJ, Stam F, van der Ploeg T, Huijgens PC, Verdonck-de Leeuw IM. Cognitive coping style (monitoring and blunting) and the need for information, information satisfaction and shared decision making among patients with haematological malignancies. Psychooncology 2015 May;24(5):564-571. [doi: 10.1002/pon.3699] [Medline: 25333875]

61. Trikalinos TA, Wieland LS, Adam GP, Zgodic A, Ntzani EE. Decision Aids for Cancer Screening and Treatment [Internet]. AHRQ Comp Effect Rev 2014:1-121 [FREE Full text] [Medline: 25632492]

62. Chang KL, Grubbs EG, Ingledew P. An analysis of the quality of thyroid cancer websites. Endocr Pract 2019 Oct;25(10):1003-1011. [doi: 10.4158/EP-2018-0595] [Medline: 31170373]

63. Air M, Roman SA, Yeo H, Maser C, Trapasso T, Kinder B, et al. Outdated and incomplete: a review of thyroid cancer on the World Wide Web. Thyroid 2007 Mar;17(3):259-265. [doi: 10.1089/thy.2006.0300] [Medline: 17381360]

64. Doubleday AR, Novin S, Long KL, Schneider DF, Sippel RS, Pitt SC. Online information for treatment for low-risk thyroid cancer: assessment of timeliness, content, quality, and readability. J Cancer Educ 2020 Feb 27:1-8 [Accessed June 15, 2021] [FREE Full text] [doi: 10.1007/s13187-020-01713-5] [Medline: 32108292]

65. Krishnamurti L, Ross D, Sinha C, Leong T, Bakshi N, Mittal N, et al. Comparative effectiveness of a web-based patient decision aid for therapeutic options for sickle cell disease: randomized controlled trial. J Med Internet Res 2019 Dec 04;21(12):e14462 [Accessed June 15, 2021] [FREE Full text] [doi: 10.2196/14462] [Medline: $\underline{31799940]}$

66. Sowan AK, Beraya AR, Carrola A, Reed C. Effect of a multimedia patient decision aid to supplement the informed consent process of a peripherally inserted central venous catheter procedure: pre-post quasi-experimental study. JMIR Med Inform 2018 Nov 28;6(4):e11056 [Accessed June 15, 2021] [FREE Full text] [doi: 10.2196/11056] [Medline: 30487117]

67. Hung Y, Wu C, Liang T, Chou S, Chen G, Wu P, et al. Developing a decision-aid website for breast cancer surgery: an action research approach. J Med Internet Res 2019 Feb 04;21(2):e10404 [Accessed June 15, 2021] [FREE Full text] [doi: 10.2196/10404] [Medline: 30714941]

68. Melnick ER, Hess EP, Guo G, Breslin M, Lopez K, Pavlo AJ, et al. Patient-centered decision support: formative usability evaluation of integrated clinical decision support with a patient decision aid for minor head injury in the emergency department. J Med Internet Res 2017 May 19;19(5):e174 [Accessed June 15, 2021] [FREE Full text] [doi: 10.2196/jmir.7846] [Medline: 28526667]

69. Yu C, Choi D, Bruno B, Thorpe K, Straus S, Cantarutti P, et al. Impact of MyDiabetesPlan, a web-based patient decision aid on decisional conflict, diabetes distress, quality of life, and chronic illness care in patients with diabetes: cluster randomized controlled trial. J Med Internet Res 2020 Sep 30;22(9):e16984 [Accessed June 15, 2021] [FREE Full text] [doi: 10.2196/16984] [Medline: 32996893]

70. Basile M, Andrews J, Jacome S, Zhang M, Kozikowski A, Hajizadeh N. A decision aid to support shared decision making about mechanical ventilation in severe chronic obstructive pulmonary disease patients (InformedTogether): feasibility study. J Particip Med 2018;10(2):e7 [Accessed June 15, 2021] [FREE Full text] [doi: 10.2196/jopm.9877] [Medline: $\underline{32461812]}$

71. Nota I, Drossaert CH, Melissant HC, Taal E, Vonkeman HE, Haagsma CJ, et al. Development of a web-based patient decision aid for initiating disease modifying anti-rheumatic drugs using user-centred design methods. BMC Med Inform Decis Mak 2017 Apr 26;17(1):51 [Accessed June 15, 2021] [FREE Full text] [doi: 10.1186/s12911-017-0433-5] [Medline: $\underline{28441950]}$

72. Maunsell R, Bloomfield S, Erridge C, Foster C, Hardcastle M, Hogden A, et al. Developing a web-based patient decision aid for gastrostomy in motor neuron disease: a study protocol. BMJ Open 2019 Dec 18;9(12):e032364 [Accessed June 15, 2021] [FREE Full text] [doi: 10.1136/bmjopen-2019-032364] [Medline: 31857308]

73. Baptista S, Sampaio ET, Heleno B, Azevedo LF, Martins C. Web-based versus usual care and other formats of decision aids to support prostate cancer screening decisions: systematic review and meta-analysis. J Med Internet Res 2018 Jun 26;20(6):e228 [Accessed June 15, 2021] [FREE Full text] [doi: 10.2196/jmir.9070] [Medline: 29945857]

74. Syrowatka A, Krömker D, Meguerditchian AN, Tamblyn R. Features of computer-based decision aids: systematic review, thematic synthesis, and meta-analyses. J Med Internet Res 2016 Jan 26;18(1):e20 [Accessed June 15, 2021] [FREE Full text] [doi: 10.2196/jmir.4982] [Medline: 26813512]

75. Staszewska A, Zaki P, Lee J. Computerized decision aids for shared decision making in serious illness: systematic review. JMIR Med Inform 2017 Oct 06;5(4):e36 [Accessed June 15, 2021] [FREE Full text] [doi: 10.2196/medinform.6405] [Medline: 28986341] 


\section{Abbreviations}

MTC: medullary thyroid carcinoma

REDCap: Research Electronic Data Capture

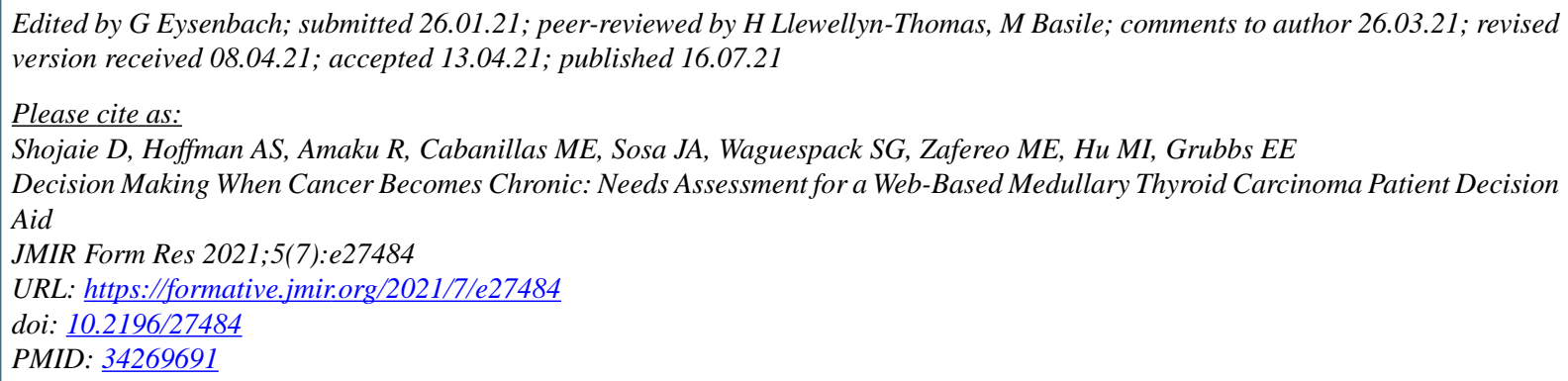

CDanielle Shojaie, Aubri S Hoffman, Ruth Amaku, Maria E Cabanillas, Julie Ann Sosa, Steven G Waguespack, Mark E Zafereo, Mimi I Hu, Elizabeth E Grubbs. Originally published in JMIR Formative Research (https://formative.jmir.org), 16.07.2021. This is an open-access article distributed under the terms of the Creative Commons Attribution License (https://creativecommons.org/licenses/by/4.0/), which permits unrestricted use, distribution, and reproduction in any medium, provided the original work, first published in JMIR Formative Research, is properly cited. The complete bibliographic information, a link to the original publication on https://formative.jmir.org, as well as this copyright and license information must be included. 